Agata Klimczak-Pawlak

University of Warsaw, Poland

\title{
Discourse completion test as a tool for the development of intercultural competence
}

\section{Introduction}

With the development of international cooperation among the European Union member states, with growing communications, flow of information, exchange of ideas, migration of people, with the slow creation of the EU culture and EU citizens comes responsibility-a responsibility of fostering intercultural competence, of preparing people of the EU to communicate, to function in and take advantage of the wealth the EU has to offer. A Union of 27 cultures, 23 languages and over 150 minority languages (European Commission 2004) is a complex mirage of cultures and languages and a union in which intercultural dialogue faces many challenges. It is clear that extra efforts have got to be made in order to secure inclusion and a breakdown- and misunderstanding-limited communication among the EU's citizens. One such safeguarding tool of inclusion, and indeed of democracy, is intercultural competence including cultural awareness and understanding. The present paper discusses the development of intercultural competences through the use of a discourse completion task (DCT) in a foreign language classroom.

Language learning supplies a perfect context for intercultural competence development and indeed, a development of an 'intercultural speaker', someone who has an ability to interact with with 'others', to accept other perspectives and perceptions in the world, to mediate between different perspectives, to be conscious of their evaluations of difference" (Byram et al. 2001: 5). Language teachers are faced with the responsibility of helping learners develop necessary 
skills and competences which will allow them to enter the multicultural scene of the European Union. They are no longer just responsible for the language education but educating an intercultural speaker with the abilities and the knowledge necessary for them to function in the EU, to work, to travel and to support democratic citizenship.

Teaching a language one has to bear in mind the different skills and competences which need to be focused on-some can be perceived as being easier and some as more difficult. The present paper aims to address the development of intercultural competence. In the present paper discourse completion task (DCT) is claimed to be an ideal tool for teachers to stimulate its development. The paper consists of three parts. In the first part focus is on intercultural competence; in the second part discourse completion task as a tool both for data collection and for teaching is discussed and finally, the third and final part of the paper aims to present practical ideas of how DCTs can be used in teaching languages.

\section{Intercultural Competence}

The importance of knowing foreign languages, or at least one foreign language, has been stressed for decades now. English has become the most widely learnt language across Europe, it is present in every European's life, be it in music, TV, advertising, school, work, or shops. Indeed, even in Polish shops we now often see the word 'sale' instead of its Polish counterpart. Regardless of the official calls for multilingual Europe English is the language one cannot afford not to know, as lack of its mastery limits one's possibilities quite substantially. Therefore, English is the most likely language to be learnt at some stage of an educated European, with some learners focusing on general English exams (like the ones offered by the Cambridge Syndicate), while others on English for special purposes. The number of language schools and the wealth of various courses available on the market is astounding and so one could easily make the assumption that if learners start learning English with one of the more renown schools and reach the advanced level, they will be able to communicate in this language with ease, especially since English seems to be omnipresent. How shocked they may be when faced with a situation in which they cannot communicate effectively in English despite years of learning vocabulary and grammar and practicing all the skills.

Unfortunately, the brutal reality is that even being a proficient user of English, and having the highest proficiency Cambridge Syndicate exam (Cambridge Proficiency in English (CPE)) passed does not guarantee that we are going to be able to communicate effectively in English. How is it then, one may ask, that despite all this knowledge, some may perceive us as rude or unclear, unable to communicate clearly? On the basis of personal experience, we can ask the following, observationbased questions: How is it possible that a Polish Member of Parliament with an 
advanced level of English, with best intentions and a belief in their politeness, can be seen as being rude by their colleagues in the European Parliament? How is it that even after years of English language education a proficient Polish speaker with a C2 level of English cannot achieve her goal of persuading a Director of Studies at a language school that he should move her to a different course, despite having all the arguments needed, and knowing she is right? How is it that one can feel completely misunderstood and confused despite all the information being communicated? How is it that an elderly lady takes offence even though an apology has been offered? What is the missing element that can explain all of the above? The ability to be successful to use English for successful communication across cultures.

Knowledge of a language is not limited to the knowledge of the code. Apart from the code, one should know which code realizations are appropriate in specific situations. Depending on one's mother tongue and culture, one might see a situation in which she broke a promise to a friend as requiring a long elaborate apology bound with explanations and self depreciation, while a person from a different culture might see the same situation as much less grave than the first person. People from different countries (languages and cultures) are different, they have varying beliefs and value systems. Naturally, some cultures are more similar than others and some are more different. We may see different things as important and different situations as requiring different reactions-both verbal and non-verbal. When we learn a foreign language then, it seems sensible that we also learn the target culture and those rules which tell us which linguistic elements are appropriate in different situations. Unfortunately, quite often what is taught and learnt is only the linguistic code and not those rules which manage communication in the target language community. Therefore, when we learn only the code of a foreign language, while using it, we tend to translate our utterances, transfer our linguistic behaviour, expectations and assumptions from our native language. When a group of people who have learnt English in such a way meet, then English serves as a common code which allows them to communicate, but it does not allow them to make common assumptions and expectations about their beliefs and behaviour. Consequently, misunderstandings can occur. If all the interlocutors have an advanced level of English and communicate with ease, they may assume they have more common ground than only the code, which is misleading, as they may assume more than they should.

The fact that our native language and culture may affect our performance in a foreign language has been noticed a long time ago and it is nothing surprising, especially not on a linguistic level. When learning any new language we translate words, phrases and sentences from and to our native language. The more complicated issue arises when we transfer our native pragmatic behaviour into the target language, especially when we do not control it. 
Intercultural experiences may be positive, but they also may be stressful, uncomfortable and as Sacru (2005) notes they may cause one's revision of identity, beliefs, attitudes and values, their position in society. What is more intercultural experiences may evoke a range of emotions from anger to relief, from fear to excitement, from envy to appreciation and they may end in either an individual rethinking and reformulating the way they view themselves and their in-group, gaining the ability to look at it from the perspective of 'the other' or just the opposite-they may resist it and deepen their pre-intercultural experience beliefs. The question then arises what knowledge, what abilities, what characteristics one needs to posses in order to be able to cope in such intercultural situations. Intercultural competence is the answer.

Intercultural competence is strongly tied to communicative competence, and that is why it is often referred to as intercultural communicative competence. Applying the concept of communicative competence to non-native language production, Kasper (2001) states that communicative competence is the speaker's ability to determine how to employ different linguistic resources so that they are appropriate with regards to their context and form. Therefore in order for learners to reach full communicative competence in a target language, they need to master what Leech (1983) and Thomas (1983) called pragmalinguistics and sociopragmatics, the first referring to "the resources for conveying communicative acts and relational or interpersonal meanings" (Kasper and Rose 2001: 2) and the second being described by Leech (1983: 10) as "the sociological interface of pragmatics". Intercultural competence, on the other hand, as conceptualised and described by Byram (1997) is composed of five intertwined and interconnected savoirs-savoirs, savoir-apprendre and savoir-comprendre, savoir-faire, savoir-être, savoir-s'engager. To these five savoirs Secru (2005) suggests adding the sixth: savoir communiquer (communicative competence).

These five savoirs can be viewed as belonging to three dimensions: knowledge, skills/ behaviour, attitudes/traits. Savoirs belongs to the knowledge dimension and constitutes "knowledge about social groups and their cultures in one's own country, and similar knowledge of the interlocutor's country on the one hand, and similar knowledge of the processes and interaction at individual and social levels, on the other hand" (Byram 1997 in Sercu 2005: 4). Savoir-apprendre, savoircomprendre and savoir-faire fall into the skills dimension with the first referring to "the capacity to learn cultures and assign meaning to cultural phenomena in an independent way" (Byram and Zarate 1997 in Sercu 2005: 4), the second to "the capacity to interpret and relate cultures" (Sercu 2005: 4) and the third to "the overall ability to act in an interculturally competent way in intercultural contact situations, to take into account the specific cultural identity of one's interlocutor and to act in a respectful and co-operative way" (ibid.). The two final savoirs, savoir-être and savoir-s'engager belong to the attitudes/traits dimension and are very much related to each other as the first refers to "the capacity and willingness 
to abandon ethnocentric attitudes and perceptions and the ability to establish and maintain a relationship between one's own and the foreign culture" (Byram 1997 in Sercu 2005: 5) and the latter to "a critical engagement with the foreign culture under consideration and one's own" (ibid.).

The development of intercultural competence is of paramount importance, however still not many resources or guidelines are available to teachers on how to actually do it. The tool advocated in this paper to be of great use in language education with the aim of the development of intercultural competence is presented in the following section.

\section{Discourse completion test-a data collection method, a teaching tool, or both?}

The most widely used instrument for data collection is speech act research has undoubtedly been discourse completion test. DCTs have first been developed as a written, non-interactive method but later modified versions have been tested for their reliability and validity. The non-interactive device consists of a description of a situation or situations to which participants of the study are asked to react. Some DCTs include a rejoinder after the prompt, while others do not.

One of the first studies in interlanguage pragmatics to use a DCT was that of Blum-Kulka's (1982). In this study a highly controlled method was employed, as situations were described by a conversation with one gap to be filled by participants. The first large scale study to employ DCTs, however, was CCSARP. In the DCT designed by Blum Kulka et al. (1989) each situation is firstly briefly described and then the prompt is followed by space for participants to write what they think they would say in a given situation, followed by a rejoinder. Additionally, the exchange could be initiated by the interlocutor. It is this model of a DCT which was most widely replicated. However, some modifications were introduced in later studies. Bardovi-Harlig and Hartford (1993), for example, also relied on a dialogue construction, but in their design the interlocutor initiated the exchange, and after the space for the participants to fill out, there was no rejoinder. Another study (Hudson, Detmer, and Brown 1995) introduced a DCT which consisted only of a description of a situation and space for a response. The main difference between this format and the previous is the lack of a rejoinder.

The significance of rejoinders has been debated as some (e.g. Blum-Kulka et al. 1989) claimed that they are needed to complete the speech act. Others, however, (eg. Bardovi-Harlig and Hartford 1993, Felix-Brasdefer 2008) did not include a rejoinder as its significance to the results was not corroborated (Rose 1993).

Another modification to the DCT has been introduced by Barron (2003) who chose a free discourse completion task (FDCT) as her instrument for data collection. In FDCT the participants were asked not to produce only one turn, but a short 
dialogue. Another variation of a written DCT is an oral DCT which supposedly allows data elicitation similar to that rendered by natural conversations (Cohen and Olshtain 1981). The next two modifications came four years apart: first in 2000 Rose designed a cartoon oral production task (COPT) and in 2004 Schauer employed a multimedia elicitation test (MET) completed by participants via computers. However, it was the DCT format proposed by Billmyer and Varghese (2000) that seems to have included most influential modifications. In their contentenriched WDCT every situation was described in much greater detail with more contextual information (time and place). When compared to the regular WDCT they found the content-enriched version rendered more elaborate and externally modified responses than the traditional WDCT.

Overall, different versions of a DCT have been heavily employed firstly, due to the ease with which they allow data to be collected and secondly, because they allow for observing how people from different cultural and linguistic background respond to the same situations with different variables controlled. For the very same reason it is argued here that DCTs make perfect tools for classroom investigations onto speech acts. Despite the fact that none of the versions of a DCT allow investigation into the dynamics of interaction, negotiation and complex realizations of speech acts, they do allow the investigation of model, or prototype, response. Kwon (2004) points out that when the aim of the study is "pragmalinguistic knowledge of the strategies and linguistic forms by which communicative acts can be implemented, and about their sociopragmatic knowledge of the context factors under which particular strategies and linguistic choices are appropriate" (p. 342) then a DCT is an adequate instrument. It is undoubtedly not an adequate instrument, however, should one want to investigate the dynamics of a conversation, negotiations, turntaking, sequencing of action or pragmatic cues.

Since DCTs are such a popular tool in data collection it seems reasonable that they should also be used in language teaching. Indeed, the usefulness of DCTs in cross-cultural awareness raising has been noted among others by Kasper and Rose 2001, Kondo (2010), Klimczak (2011), Ishihara and Cohen (2012) and the following section aims to outline several practical ideas on how to employ DCTs in a language classroom.

\section{Several practical ideas on how to use DCTs for the development of intercultural competence}

All of the ideas presented below are suitable for learners with intermediate language abilities, however undoubtedly the more advanced the learners are the more detailed the analysis of different situations is possible with a more in-depth linguistic analysis. The prerequisite for the realization of the following ideas is for a school to cooperate with schools from other EU countries. 


\subsection{Perceptions of politeness}

The aim of 'perception of politeness' classes are raising Ss' awareness that what may seem polite to some people may seem impolite to others. Firstly, it is important that learners realise that differences in perceptions of politeness may vary not only cross-culturally, but also within their own culture. Before one begins investigating cross-cultural differences it is good to be aware of the diversity present around us. Uncovering differences learners never before realized or noticed allows selfreflection and a deeper understanding of the complexities surrounding crosscultural communication. The steps listed below are, as all ideas presented in this section, tentative and open to modification.

1. T prepares a set of situations (2-3), distributes them and asks Ss to provide what they believe they would say in given situations.

2. Ss are asked to walk around the class, talk to their classmates and compare what they wrote noting down differences.

3. T asks what differences they observed and a discussion regarding reasons for those differences/ similarities follows.

4. T divides the class into groups and asks them to prepare their own situations/ DCT. T supervises the process and checks grammar and vocabulary.

5. Ss are asked to collect as many responses to their DCTs as possible from students from the school.

6. Once the Ss finish the collection process either $\mathrm{T}$ assists $\mathrm{Ss}$ in analysing the responses providing them with strategies etc. to focus on, or leaves the task of uncovering possible differences entirely to the Ss.

7. Ss present their findings and a discussion follows.

Ideally the project described above would take place in FL within the school first and then a similar project in L1 would follow. Ss could be asked to create a DCT in their mother tongue and collect responses from their families, family friends etc. noting down the age of respondents. This could lead to an even better understanding of the complexities discussed.

\subsection{The basic cross-cultural differences lesson(s)}

Possibly the easiest and most straightforward version of an intercultural competence centred class with the use of a Discourse Completion Test is this 'basic version' - it does not require any additional work from the learners and very little from the teacher. Firstly, the teacher has to make a decision on what situations would best suit his/her purposes and design a DCT. Since it is not a DCT meant for research purposes, but for teaching, the teacher does not need to think about even distribution, distractors etc. Before the class the teacher also needs to contact a teacher from their partner school and ask him/her to distribute the same DCT 
s/he wants to use in their class, scan and send them to him/her. Once the teacher has those filled out DCTs he/she needs to print them out, as well as empty DCTs for his/her class to fill out. After an appropriate lead in, the teacher can distribute the DCT and ask the students to write what they believe is an appropriate answer/ or what they would say in such situations. Pair work could follow with the students being asked to compare and discuss what they wrote. Afterwards the teacher distributes DCTs filled out by learners from the partner school and students are asked to work in groups and note the differences between the responses provided by their peers from another country and those they provided themselves. Once the differences / similarities are discussed and noted the learners are asked to write to their peers from abroad what surprised them/ what they liked/ what they found to be similar and to ask further questions with regards to culture-specific use of language and politeness norms.

The above can be summarized in the following points:

1. Teacher (T) creates a DCT-composed of as many or as little situations s/he finds suitable and dealing with issues of his/her liking (e.g. refusals).

2. T asks a T from a partner school to collect responses to this DCT among their students, scan and email them back.

3. In class: T gives students (Ss) the DCT asking them to provide responses they see as being most suitable or responses they believe they would produce in given situations.

4. Ss compare and discuss their responses.

5. $\mathrm{T}$ distributes responses obtained from the partner school; Ss compare and discuss.

6. Ss write to their peers from the partner school what they found to be similar/ different/ surprising when comparing their responses.

7. Should there be such possibility this activity could and should lead to cooperation between the learners from both schools in future DCT comparison and communication/ exchange of observations etc. Best follow-up would include 'communication' sessions where Ss from both schools could talk directly learning about their differences and similarities.

The above plan can naturally be modified depending on the number of schools cooperating and available equipment (as presented in the next section).

\subsection{The extended cross-cultural differences lesson(s)}

In the extended version the steps 1-7 described above remain and the following are added:

1. Ss are asked to think of situations which can render different reactions from people from different countries (predicting cross-cultural differences) and to present justifications for their choice of situations. 
2. Ss are asked to work in groups and put together a DCT which they think could result in interesting responses.

3. Each group is asked to contact learners from their partner schools and ask them to fill in their DCT. Student communication should be monitored by teachers from all partner schools involved.

4. Once Ss collect the necessary data and analyse it, they are encouraged to contact one or more students who took part in their project and record an interview (via Skype for example).

5. Ss are then asked to find out more about the culture of their participants and prepare a presentation for their classmates, during which they would present the information they collected on the culture of their participants, their DCT along with the interview.

6. Once the presentations are over the teacher can turn these mini-projects into a more long-term project be it a website or a school intercultural centre where Ss could add new findings and facts throughout the year.

\subsection{Rating politeness}

Once learners are aware of the differences present in the realization of different speech acts in their L1 and L2 it might be a good idea to draw Ss' attention to levels of politeness and this too can be done with the use of a DCT.

1. T either distributes a DCT with a few situations or describes situations and asks Ss to write what they believe they would say in such situations / what they believe is most appropriate to say in such situations.

2. T asks Ss to share what they wrote-some responses may be the same, some may be different. Ss are asked to decide which response is the most polite and which is the least. A discussion follows with T drawing Ss' attention to issues of social distance and power relations.

3. T gives Ss a DCT with some responses filled in (preferably authentic) and after instructing Ss that they are to imagine they are from country X trying to abide by this country X's norms they are asked to rate the provided responses according to their politeness level. A discussion follows with the comparison of the Ss' ratings and the T's commentary.

4. Ss are then asked to create DCTs in groups and ask their classmates to fill them in. Afterwards they choose three responses provided by their peers and create a rating exercise similar to the one they were asked to do in step 3. Then either Ss themselves send them to their peers from partner schools or T sends their rating exercises to partner school/s' language teacher/s for them to conduct the exercise in class, collect, scan and email back.

5. Discussion of results follows with each group presenting their findings first.

An extension to this idea is presented below. 


\subsection{Challenging stereotypes}

The final idea aimed at developing intercultural competence presented here is one which aims at checking Ss' beliefs and views of people from different cultures. As in previous lesson ideas here too Ss are asked to fill out a DCT (either prepared by T or Ss). The only difference is that they are asked not to fill it in as themselves but as people from different countries (T might want to prepare pieces of paper on which names of different countries would be written down and allow Ss to draw one). A lesson centred around the beliefs of Ss on how people from different countries communicate may serve as ignition to an in-depth analysis of the stereotypes Ss have and beliefs they hold.

\section{Conclusion}

Language teachers nowadays are no longer only guides through linguistic intricacies of a given language/s helping their learners acquire communicative competence, they are now mediators of cultures, empathetic observers and facilitators leading their pupils through the web of intercultural communication preparing them to live, work and succeed in a diverse world. The activities described above certainly do not exhaust the potential of DCTs-a tool which is possibly the easiest and most accessible tool to teachers and pupils, but only hope to inspire teachers to take advantage of this tool and explore cross-cultural differences with their students.

\section{References}

Bardovi-Harlig, K., Hartford B,S. 1993. "Learning the rules of academic talk: A longitudinal study of pragmatic development". Studies in Second Language Acquisition 15: 279-304.

Barron, A. 2003. Acquisition in Interlanguage Pragmatics. Learning how to do things with words in a study abroad context. Amsterdam/Philadelphia: Benjamins.

Billmyer, K., Varghese, M.M. 2000. Investigating instrument-based pragmatic variability: Effects of enhancing discourse completion tests. Applied Linguistics, 21/4: 517-552.

Blum-Kulka, S. 1982. Learning how to mean in a second language: A study of the speech act performance of learners of Hebrew as a second language. Applied Linguistics, 3(1): 30-59.

Blum-Kulka, S., House, J., and Kasper, G. (Eds.). 1989. Cross-cultural pragmatics: Requests and apologies. Norwood: Ablex Publishing.

Byram, M. 1997. Teaching and Assessing Intercultural Communicative Competence. Clevedon: Multilingual Matters.

Byram, M., Zarate, G. 1997. Definitions, objectives and assessment of sociocultural competence. In M. Byram, G. Zarate and G. Neuner (Eds.), Sociocultural competence in language learning and teaching. Strasbourg: Council of Europe Publishing.

Byram, M., Nichols, A. and Stevens, D. (Eds.) 2001. Developing Intercultural Competence in Practice. Clevedon: Multilingual Matters. 
European Commission. 2004. Many tongues, one family. Retrieved from http://ec.europa.eu/ publications/booklets/move/45/en.pdf

Félix-Brasdefer, C. 2008. Politeness in Mexico and the United States: A Contrastive Study of the Realization and Perception of Refusals. Amsterdam: Benjamins.

Hudson, T., Detmer, E. and Brown J.D. 1995. Developing Prototypic Measures of Cross-Cultural Pragmatics. Honolulu, Hawaii. University of Hawaii Press.

Kasper, G. 2001. Classroom research on interlanguage pragmatics. In K.R. Rose, G. Kasper (Eds.), Pragmatics in language teaching. Cambridge: Cambridge University Press.

Ishihara, N., Cohen, A.D. 2012. Teaching and Learning Pragmatics: Where Language and Culture Meet. Longman.

Klimczak, A. 2011. British Politeness in a Polish ESL/EFL Clessroom?. In M. Pawlak (Ed.), Extending the Boundaries of Research on Second Language Learning and Teaching, edited by. Berlin: Springer.

Leech, G. 1983. Principles of Pragmatics. London: Longman.

Rose, K.R. 1993. Sociolinguistic consciousness-raising through video. The Language Teacher 17: 7-9.

Rose K.R., Kasper G. 2001. Pragmatics in language teaching. In K.R. Rose, G. Kasper (Eds.), Pragmatics in language teaching. Cambridge: Cambridge University Press.

Schauer, G. 2004. May you speak louder maybe: interlanguage pragmatic development in requests. EUROSLA Yearbook, 4: 253-272.

Sercu, L., Bandura E., Castro P., Davcheva L., Laskaridou Ch., Lundgren U., Garcia M., Ryan P. 2005. Foreign Language Teachers and Intercultural Competence. An International investigation. Clevedon-Buffalo-Toronto: Multilingual Matters Ltd.

Thomas, J. 1983. Cross-cultural pragmatic failure. Applied Linguistics, 4, 91-112. 